\title{
Effect of sodium fluoride on germination, seedling growth and photosynthetic pigments in Cicer arietinum L. and Hordeum vulgare L.
}

\begin{abstract}
Fluoride is a toxic substance present in air, water and soil and Industrial growth as well as human activities are responsible for increasing its level in the environment which inhibit the plant growth and productivity. In view of this, present study was undertaken to investigate the effects of sodium fluoride $(\mathrm{NaF})$ on germination, seedling growth and photosynthetic pigments in Chickpea (Cicer arietinum L.) and Barley (Hordeum vulgare L.) using $0,2.5,5.0,10.0 \mathrm{mM} \mathrm{NaF}$ concentrations. At the end of 9 days treatment period, reduction in germination parameters (i.e. germination $\%$, emergence $\%$, emergence rate and vigor index) were found more pronounced in Chickpea as compared to Barley. Same trend was also observed for mobilization efficiency (ME) which decreased in Chickpea seedlings at higher concentrations. During early seedling growth, the root and shoot length, and biomass of Chickpea seedlings were compromised with increasing NaF level. However, in contrast to Chickpea, root and shoot length of Barley seedling were stimulated at $1.0 \mathrm{mM} \mathrm{NaF}$ concentration and 1.0 and $2.5 \mathrm{mM} \mathrm{NaF}$ stimulated root and shoot biomass too in barley cultivar. Higher $\mathrm{NaF}$ levels turned inhibitory to length and biomass of root and shoot tissues in both the crops. Comparison of photosynthetic pigments in Chickpea revealed increase in total chlorophyll, Chlorophyll a and b and carotenoids at $1.0 \mathrm{mM}$ and $2.5 \mathrm{mM}$ over control while, the synthesis of all these pigments were reduced in case of Barley with increasing $\mathrm{NaF}$ concentrations. This study revealed Chickpea to be more susceptible to the toxic nature of fluoride $(\mathrm{F})$ than Barley during germination and seedling stage.-
\end{abstract}

Keywords: Cicer arietinum, Hordeum vulgare, NaF, germination, vigor index, mobilization efficiency, seedling growth, photosynthetic pigments
Volume 3 Issue 4 - 2018

Priti Sachan, Nand Lal

Department of Life Sciences, C.S.J.M. University, India

Correspondence: Nand Lal, Department of Life Sciences, C.S.J.M. University, Kanpur-208024, India,

Email nl_pr@yahoo.co.in

Received: January 30, 2018 | Published: August 31, 2018

\section{Introduction}

Fluoride (F) is an anion of halogen family and $13^{\text {th }}$ most abundant element of the earth crust and occurs at about $0.3 \mathrm{gkg}^{-1}$ of earth's crust. Fluorides are naturally occur in the form of sodium fluoride or hydrogen fluoride in rocks, coal, clay and soil and released into the environment through the weathering of minerals, emissions from volcanic ash and marine aerosols. ${ }^{1}$ In water, inorganic fluorides usually remain in solution (as fluoride ions) under conditions of relatively low $\mathrm{pH}$ and hardness. Though, $\mathrm{F}$ is considered as absolutely non- essential element for plants, ${ }^{2}$ its presence in soil, air and water causes alterations in physiological, biochemical and structural activities in plants, ${ }^{3}$ sometimes even without showing any visible symptoms of injury. Jha et al., ${ }^{3}$ reported that the order of retention of fluoride in onion was found to be roots $>$ shoot $>$ bulb. Certain plant species have been observed to be injured as a result of the accumulations of excessive fluoride from the atmosphere. The annual global release of hydrogen fluoride from volcanic sources through passive degassing and eruptions range from 60 to 6,000 kilo tons. From which approximately $10 \%$ may be introduced directly into the stratosphere. ${ }^{4}$ Fluoride can also be deposited into soil from several anthropogenic sources i.e. production of phosphate fertilizers, pesticides (such as sulfuryl fluoride), detergents, bricks, tiles and ceramics, and atmospheric pollution from industrial activities (used in aluminum production and as a flux in the steel and glass fiber industries) and burning of fossil fuels. ${ }^{5}$ Among thermo stable fluoropolymer plastics, polytetrafluoroethylene (PTFE) is very common/useful fluorine containing plastic sold and used domestically as cooking utensils due to its heat resistance and nonstick properties. Gaseous fluoride enters into the plant leaves through stomata whereas soil fluoride enters through absorption by roots and subsequently translocated into shoot. Certain plant species accumulate $\mathrm{F}$ in their roots and shoots at higher concentrations up to $4000 \mu \mathrm{gg}^{-1} \mathrm{~F}$ without showing any signs of toxicity. ${ }^{6}$ However, most of other plants show signs of toxicity at relatively much lower $\mathrm{F}$ concentration. F affects plant growth and development by interfering with several metabolic pathways associated with photosynthesis, respiration, protein synthesis, carbohydrate metabolism, and nucleotide synthesis. ${ }^{7,8}$ Several studies have been reported on F contamination of soil and its effects on different plant species ${ }^{6}$ including cereals ${ }^{9}$ and vegetables. ${ }^{10}$ However, there is little information available on the effects of $F$ on the germination and early growth characteristics of commonly grown crop plants by farmers. The importance of seed germination in plant growth is widely recognized and its study has been used as a model for investigating elemental toxicity. Hence, the objective of this study was to investigate and measure the effects of $\mathrm{F}$ on the germination, early growth characteristics of seedlings and content of photosynthetic pigments in two important Indian food crops namely Chickpea (Cicer arietinum L.) and Barley (Hordeum vulgare L.).

\section{Materials and methods}

Certified seeds of Cicer arietinum L. cv. Azad and Hordeum vulgare L. cv. K125 (Azad) were sterilized with $0.1 \%(\mathrm{w} / \mathrm{V})$ of Mercuric chloride solution for 5 minutes followed by thorough 
repeated rinsing with distilled water. For germination studies, 100 surface sterilized seeds were sown in $120 \mathrm{~mm}$ diameter Petri dishes containing equal volume of sterilized sand. Each sand- filled Petri dish was added with $80 \mathrm{ml}$ of 0 (distilled water, control), 1.0, 2.5, 5.0, and $10.0 \mathrm{mM} \mathrm{NaF}$ solution prepared from a $20.0 \mathrm{mM}$ stock solution. Counts were made on each day for seedlings emerging above the sand mix to in order to estimate \% emergence and emergence rate. The experiments were terminated on $9^{\text {th }}$ day and the seeds/seedlings were used for estimating final percent seed germination, root and shoot length, root and shoot biomass, seedling vigour index, mobilization efficiency and content of photosynthetic pigments (Total chlorophyll, Chlorophyll a, chlorophyll $\mathrm{b}$ and carotenoids).

Germination percentage in each fluoride treatment was recorded on $9^{\text {th }}$ day after sowing according to following formula:

$$
\text { G.P. }=\frac{\text { Number of germinated seeds }}{\text { Total number of seeds }} \times 100
$$

The numbers of emerging seedlings above sand mix were recorded daily up to 9 days and values of each count were summed at the end of 9 days to compute \% emergence and emergence rate according to Maguire. ${ }^{11}$

$$
\% \text { Emergence }=\frac{\text { Number of seedlings emerging the soil mix }}{\text { Total number of germinated seeds }} \times
$$

Emergence rate $=\frac{\text { Number of seedlings emerging above the soil }}{\text { Days to final count }}$

Vigor index of seedlings obtained at various $\mathrm{NaF}$ treatments was calculated according to the formula given by Abdul- Baki et al. ${ }^{12}$

Vigor Index $=\%$ normal germination $\times$ Average hypocotyl length

Mobilization efficiency (ME) of seedlings obtained with each $\mathrm{NaF}$ treatment was estimated by the method of Mohan et al. ${ }^{13}$ using the following formula:

$$
M E=\frac{\text { Dryweight of seedlings }}{\text { Dry weight of cotyledon }} \times 100
$$

For estimation of chlorophylls (chl) and Carotenoids, 9 day old Petri dish grown seedlings were harvested separately and $100 \mathrm{mg}$ leaf tissue from randomly chosen seedlings was placed in $2 \mathrm{ml}$ dimethyl sulfoxide (DMSO) liquid in dark for overnight period according to Hiscox et al., ${ }^{14}$ for pigment extraction. The extract was centrifuged at $5000 \mathrm{rpm}$ for 5 minutes and then the absorbance (O.D.) of leaf extract (supernatant) was recorded at 480, 510, 645 and $663 \mathrm{~nm}$ using spectrophotometer. The pigment value of total chl, $\mathrm{Chl} \mathrm{a,} \mathrm{Chl} \mathrm{b}$ and carotenoids were estimated according to Anon ${ }^{15}$ and Lichtenthaler et al. ${ }^{16}$

$$
\begin{aligned}
& \text { Chl a }=12.7_{\mathrm{x}}\left(\text { O.D. }{ }_{663}\right)-2.69_{\mathrm{x}}\left(\text { O.D. }_{645}\right) \\
& \mathrm{Chl} b=22.9_{\mathrm{x}}\left(\text { O.D. }{ }_{645}\right)-4.68_{\mathrm{x}}\left(\text { O.D. }_{663}\right) \\
& \text { Total Chl }=20.2_{\mathrm{x}}\left(\text { O.D. }_{645}\right)+8.02_{\mathrm{x}}\left(\text { O.D. }_{663}\right) \\
& \text { Carotenoids }=7.6\left(\text { O.D }_{480}-1.49 \times{ }_{x} \text { O.D } D_{510}\right)
\end{aligned}
$$

The actual pigment content (mg/g FW) was computed as Pigment value ${ }_{\mathrm{X}} \mathrm{V} / 1000_{\mathrm{x}} 1 / \mathrm{W}$, where $\mathrm{V}$ is the volume of DMSO extract (in $\mathrm{ml}$ ) and $\mathrm{W}$ is the weight of the leaf tissue used (in $\mathrm{g}$ ).

\section{Result and discussion}

The effects of $\mathrm{NaF}$ on various germination parameters are summarized in Table 1. Data of the Table 1 clearly indicate that both chickpea and barley seeds treated with various levels of $\mathrm{NaF}$ exhibited a marked reduction in $\%$ germination, $\%$ emergence, emergence rate and vigor index. The mobilization efficiency in seedlings also showed gradual reduction with increase in the level of $\mathrm{NaF}$ in soil. In both cases of chickpea and barley maximum (100\%) germination was recorded in case of control and minimum ( 5 and $75 \%$, respectively) at $10.0 \mathrm{mM} \mathrm{NaF}$ level. These observations on germination behavior are in conformity with the findings of Singh et al. ${ }^{17}$ and Iram et al., ${ }^{18}$ 00 in case of Raphanus sativus L. and Abelmoschus esculentus L., respectively, who reported the inhibition of root and shoot elongation and biomass production by sodium fluoride treatments. Shaddad et al., ${ }^{19}$ also observed adverse effect of $\mathrm{NaF}$ on seed germination and seedling growth in Zea mays L., Helianthus annus L. and Vicia faba L. during exposure to varying levels of $\mathrm{CdCl}_{2}, \mathrm{NaF}$ and 2,4- DNP individually. Seed germination is an energy driven developmental process and requires rapid hydrolysis of reserve food materials along with high rate of respiration. Fresh weight and dry weight decreased monotonically in both the test crops with increasing fluoride concentration due to reduction of metabolic activity in presence of fluoride because germination is a one kind of metabolism and fluoride acts as a metabolic inhibitor. ${ }^{20} \mathrm{Yu}^{20}$ exposed mung bean seeds to 10.0 $\mathrm{mM} \mathrm{NaF}$ and recorded F- induced inhibition of ATPase and 5'nucleotidase during germination which turned to be correlated with lowered amylase and lipase activity. Vigor index of seedlings in both the test crops was found maximum (1624 and 1013, respectively) in control and reached minimum (32 and 427, respectively) in $10.0 \mathrm{mM}$. The speed of decrease in vigour index was much faster in chickpea as compared to barley in presence of $\mathrm{NaF}$. Similar reduction in vigor index by fluoride compounds has also been reported in Triticum aestivum. ${ }^{21}$ Mobilization efficiency of seeds was also compromised with shifting from lower to higher fluoride concentrations in case of chickpea. ME in barley seedlings could not be determined due unavailability of cotyledonary tissue as the same was fully utilized/ exhausted by growing roots and shoots.

Table I Effect of different NaF concentrations on seed germination parameters in Chickpea and Barley

\begin{tabular}{llllll}
\hline NaF (in mM) & Germination \% & Emergence \% & Emergence rate & Vigor Index & Mobilization efficiency \\
\hline \multicolumn{2}{l}{ Chickpea cv. Azad } & & & & \\
\hline Control & 100 & 100 & 35.5 & 1624 & 200 \\
$1.0 \mathrm{mM}$ & 93 & 80 & 26.95 & 980 & 183 \\
$2.5 \mathrm{mM}$ & 91 & 80 & 24.74 & 921 & 182 \\
$5.0 \mathrm{mM}$ & 87 & 60 & 18 & 469 & 164 \\
\hline
\end{tabular}


Table continued.

\begin{tabular}{llllll}
\hline NaF (in mM) & Germination \% & Emergence \% & Emergence rate & Vigor Index & Mobilization efficiency \\
\hline $10.0 \mathrm{mM}$ & 5 & 0 & 1.66 & 32 & 153 \\
\hline Barley cv. K $\mathbf{2 5}$ (Azad) & & & & \\
\hline Control & 100 & 95 & 30.36 & 1013 & $*$ \\
$1.0 \mathrm{mM}$ & 93 & 88 & 22.53 & 941 & $*$ \\
$2.5 \mathrm{mM}$ & 90 & 86 & 21.68 & 833 & $*$ \\
$5.0 \mathrm{mM}$ & 83 & 80 & 20.68 & 700 & $*$ \\
$10.0 \mathrm{mM}$ & 75 & 70 & 19.22 & 427 & $*$ \\
\hline
\end{tabular}

*ME could not be determined due to complete exhaust of cotyledon

The effect of $\mathrm{NaF}$ was found to vary among different plant species with respect to their roots and shoots development (Table 2 ). In the present study, the root and shoot growth (in terms of length) of Chickpea, revealed inhibitory effect at even at lowest $\mathrm{NaF}$ concentration tested (i.e. $1.0 \mathrm{mM}$ ) as compared to control. The degree of inhibition of length was much higher in root in comparison to shoot. The data on root and shoot biomass almost followed the trend observed with length parameter but a drastic decrease in root biomass was recorded during increase from 5.0 to $10.0 \mathrm{mM} \mathrm{NaF}$. Fluoride causes reduction in root length and shoots length due to imbalanced nutrient uptake by seedlings. ${ }^{22}$ These findings are in conformity with the study of Singh et al. ${ }^{17}$ and Iram et al., ${ }^{18}$ on Raphanus sativus L. and Abelmoschus esculentus L., respectively wherein they reported the inhibition of root and shoot elongation and biomass by sodium fluoride treatments. Such a reduction of biomass with increasing $\mathrm{F}$ concentration has also been earlier reported by Jha et al. ${ }^{3}$ However, $1.0 \mathrm{mM} \mathrm{NaF}$ level showed stimulatory effects on both (length and biomass) the parameters of root and shoot in case of Barley. Further increase in $\mathrm{NaF}$ concentration beyond $1.0 \mathrm{mM}$ led to reduction in length and biomass of root and shoot in barley as was found in case of chickpea on comparable F concentrations. Thus, barley showed some tolerance towards $\mathrm{NaF}$ at lower $(1.0 \mathrm{mM})$ concentration. The degree of reduction in length and biomass of root and shoot was lesser in barley as compared to chickpea. This differential response of the root and shoot developments in presence of $\mathrm{NaF}$ in both the test plants of the present study can be attributed to the taxonomic differences amongst the two plant species. In a study with fluoride applied (aerially on leaves and systemically via roots) Vicia faba plants, the ability of roots to accumulate higher amount of $F$ than that of the shoot system was noted, which may well explain as to why in our study we found the roots of barley were relatively more tolerant than the shoots (with biomass production of 116.74 and $116.42 \mathrm{mg}$ ) at 1.0 and $2.5 \mathrm{mM} \mathrm{NaF}$ concentrations, respectively. ${ }^{23}$ This fact also conforms to previous observation of relatively high uptake and accumulation of $\mathrm{F}$ in both grass and legume species ${ }^{6}$ and may account for higher phytotoxicity to root tissues.

Table 2 Effect of different NaF concentrations on early root and shoot growth in Chickpea and Barley

\begin{tabular}{|c|c|c|c|c|c|c|}
\hline \multirow{2}{*}{$\mathrm{NaF}$ (in $\mathrm{mM}$ ) } & \multicolumn{3}{|c|}{ Length (cm) } & \multicolumn{3}{|c|}{ Fresh Weight (g) } \\
\hline & Root* & Shoot* & Root : Shoot ratio & Root* & Shoot* & $\begin{array}{l}\text { Root : shoot } \\
\text { ratio }\end{array}$ \\
\hline \multicolumn{7}{|c|}{ Chickpea cv.Azad } \\
\hline Control & $16.04 \pm 0.36$ & $18.62 \pm 0.45$ & 0.861 & $196.40 \pm 4.36$ & $332.76 \pm 8.15$ & 0.576 \\
\hline $1.0 \mathrm{mM}$ & $12.06 \pm 0.27$ & $18.58 \pm 0.47$ & 0.649 & $187.66 \pm 4.86$ & $319.72 \pm 8.16$ & 0.587 \\
\hline $2.5 \mathrm{mM}$ & $11.32 \pm 0.26$ & $13.96 \pm 0.42$ & 0.643 & $|5| .40 \pm 3.48$ & $13.96 \pm 0.42$ & 0.544 \\
\hline $5.0 \mathrm{mM}$ & $7.64 \pm 0.20$ & $14.90 \pm 0.45$ & 0.512 & $127.23 \pm 2.99$ & $231.96 \pm 6.82$ & 0.548 \\
\hline $10.0 \mathrm{mM}$ & $6.04 \pm 0.18$ & $12.40 \pm 0.32$ & 0.487 & $96.34 \pm 2.46$ & $231.32 \pm 6.55$ & 0.432 \\
\hline \multicolumn{7}{|c|}{ Barley cv. KI 25 (Azad) } \\
\hline Control & $9.93 \pm 0.23$ & $15.86 \pm 0.48$ & 0.626 & $71.70 \pm 1.65$ & $165.43 \pm 4.79$ & 0.433 \\
\hline $1.0 \mathrm{mM}$ & $10.26 \pm 0.24$ & $|4.46 \pm 0.3|$ & 0.98 & $116.74 \pm 2.80$ & $172.86 \pm 5.19$ & 0.675 \\
\hline $2.5 \mathrm{mM}$ & $9.06 \pm 0.21$ & $13.96 \pm 0.42$ & 0.648 & $116.42 \pm 2.79$ & $169.76 \pm 4.58$ & 0.71 \\
\hline $5.0 \mathrm{mM}$ & $8.55 \pm 0.21$ & $12.32 \pm 0.32$ & 0.693 & $72.74 \pm 1.82$ & $153.40 \pm 4.44$ & 0.474 \\
\hline $10.0 \mathrm{mM}$ & $5.50 \pm 0.14$ & $1 \mathrm{I} .0 \pm 0.28$ & 0.5 & $43.34 \pm 1.08$ & $136.9 \pm 3.63$ & 0.316 \\
\hline
\end{tabular}

*Values are expressed as mean \pm s.d

Changes in the content of photosynthetic pigments in seedlings obtained on various $\mathrm{NaF}$ treatments are summarized in Table 3. In case of Chickpea treatment with 1.0 and $2.5 \mathrm{mM} \mathrm{NaF}$ showed stimulation in total chl (2.98 and $3.06 \mathrm{mg} / \mathrm{g}$, respectively) over the control. This increase of chlorophyll in presence of $\mathrm{F}$ is an exception observation and differs from majority of previous studies in range of species ${ }^{6}$ including another cultivar (Anuradha) of C. arietinum. ${ }^{24}$ In a study on Triticum aestivum, Tomar et al., ${ }^{25}$ reported steady increase in the length of root and shoot and chlorophyll contents by 20 and $40 \mathrm{~g} /$ $\mathrm{ml} \mathrm{NaF}$. The present observations in C. arietinum cv. Azad conform to results of Tomar et al., ${ }^{25}$ and such may be due to genotype- specific response to fluoride stress. Carotenoid content was also stimulated at 1.0 and $2.5 \mathrm{mM} \mathrm{NaF}$ and reached maximum $(1.186 \mathrm{mg} / \mathrm{g})$ at 2.5 $\mathrm{mM} \mathrm{NaF}$ whereas it decreased at subsequent higher levels of $\mathrm{NaF}$ and was recorded minimum $(0.973 \mathrm{mg} / \mathrm{g}$, lesser than control $)$ at 10.0 $\mathrm{mM}$ concentration Increase in $\mathrm{NaF}$ to 5.0 and $10.0 \mathrm{mM}$ caused a rapid 
decrease in total chlorophyll and as well as in chlorophyll a, chlorophyll $\mathrm{b}$ and carotenoids. Comparison of chl a: chl b ratio revealed that at 1.0 and $2.5 \mathrm{mM} \mathrm{NaF}$ chlorophyll changes were mediated mainly through chlorophyll $\mathrm{b}$ whereas at 5.0 and $10.0 \mathrm{mM}$, chlorophyll changes were mediated through both chlorophyll a and $\mathrm{b}$. Total chl : carotenoid ratio varied within a narrow range in both chickpea and barley and did not indicate a clear increasing/decreasing pattern.

On the contrary to the Chickpea, in case of Barley the content of all photosynthetic pigments i.e. total chlorophyll, chlorophyll $a, b$ and carotenoids showed significant reduction even at the lowest (1.0 $\mathrm{mM}$ ) NaF concentration. This decrease may be either due to inhibition of chlorophyll biosynthesis (as high $\mathrm{F}$ was found to reduce the availability of $\mathrm{Fe}^{2+}$ ions which are essential for chlorophyll synthesis), or due to enhanced breakdown of chlorophyll during fluoride stress. ${ }^{6}$ Carotenoids are accessory pigments in photosynthetic systems and protect chlorophyll against oxidative stress. There was a clear decreasing trend in chlorophyll contents in barley with increasing fluoride levels. Comparison of chl a: chl b ratio revealed that till 5.0 $\mathrm{mM} \mathrm{NaF}$ chlorophyll changes were mediated through both chlorophyll $a$ and $b$ but at $10.0 \mathrm{mM}$ largely through chlorophyll $\mathrm{b}$. In a recent study conducted by Ram et al., ${ }^{26}$ on growth and development of seedlings of watermelon (Citrullus lanatus), it was found that increasing $\mathrm{NaF}$ concentration decreased the $\mathrm{Chl}$ a and $\mathrm{Chl} \mathrm{b}$, total chl and carotenoids content as compared to control seedlings.

Table 3 Changes in different photosynthetic pigments in Chickpea and Barley seedlings under different NaF

\begin{tabular}{|c|c|c|c|c|c|c|}
\hline $\begin{array}{l}\mathrm{NaF} \text { (in } \\
\mathrm{mM} \text { ) }\end{array}$ & $\begin{array}{l}\text { Total Chl* } \\
(\mathrm{mg} / \mathrm{g})\end{array}$ & $\begin{array}{l}\text { Chl a* } \\
\text { (mg/g) }\end{array}$ & $\begin{array}{l}\text { Chl b* } \\
\text { (mg/g) }\end{array}$ & $\begin{array}{l}\text { Carotenoids* } \\
(\mathrm{mg} / \mathrm{g})\end{array}$ & $\begin{array}{l}\text { Chl a: Chl b } \\
\text { ratio }\end{array}$ & $\begin{array}{l}\text { Total chl : carotenoid } \\
\text { ratio }\end{array}$ \\
\hline \multicolumn{7}{|c|}{ Chickpea cv.Azad } \\
\hline Control & $2.79 \pm 0.06$ & $2.16 \pm 0.05$ & $0.633 \pm 0.01$ & I. $105 \pm 0.02$ & 3.412 & 2.524 \\
\hline $1.0 \mathrm{mM}$ & $2.98 \pm 0.08$ & $2.25 \pm 0.06$ & $0.734 \pm 0.02$ & $1.142 \pm 0.03$ & 3.065 & 2.609 \\
\hline $2.5 \mathrm{mM}$ & $3.06 \pm 0.07$ & $2.30 \pm 0.07$ & $0.759 \pm 0.02$ & I. $186 \pm 0.03$ & 3.03 & 2.58 \\
\hline $5.0 \mathrm{mM}$ & $2.26 \pm 0.05$ & $1.83 \pm 0.06$ & $0.432 \pm 0.01$ & $0.845 \pm 0.02$ & 4.236 & 2.674 \\
\hline $10.0 \mathrm{mM}$ & $2.5 I \pm 0.06$ & $1.97 \pm 0.07$ & $0.503 \pm 0.01$ & $0.973 \pm 0.03$ & 3.916 & 2.579 \\
\hline \multicolumn{7}{|c|}{ Barley cv. KI 25 (Azad) } \\
\hline Control & $2.49 \pm 0.06$ & $1.87 \pm 0.04$ & $0.584 \pm 0.01$ & $0.942 \pm 0.03$ & 3.202 & 2.643 \\
\hline $1.0 \mathrm{mM}$ & $2.14 \pm 0.05$ & $1.60 \pm 0.04$ & $0.509 \pm 0.01$ & $0.842 \pm 0.02$ & 3.143 & $2.54 I$ \\
\hline $2.5 \mathrm{mM}$ & $2.04 \pm 0.05$ & $1.56 \pm 0.03$ & $0.459 \pm 0.01$ & $0.785 \pm 0.02$ & 3.398 & 2.598 \\
\hline $5.0 \mathrm{mM}$ & $\mathrm{I} .8 \mathrm{I} \pm 0.04$ & $1.36 \pm 0.04$ & $0.417 \pm 0.01$ & $0.689 \pm 0.02$ & 3.261 & 2.626 \\
\hline $10.0 \mathrm{mM}$ & $1.35 \pm 0.03$ & $1.05 \pm 0.04$ & $0.279 \pm 0.01$ & $0.522 \pm 0.02$ & 3.763 & 2.586 \\
\hline
\end{tabular}

*Values are expressed as mean \pm s.d

\section{Conclusion}

In present study, $\mathrm{NaF}$ impaired the seed germination and seedlings growth in both the test crops (Chickpea and Barley) and the adverse effects were seen more pronounced in case of Chickpea. Photosynthetic pigments (chl a, b and carotenoid) were also adversely affected by increased $\mathrm{NaF}$ concentration in both the crops.. Overall, this study shows differential tolerance of chickpea and barley towards $\mathrm{NaF}$ and provides information about how $\mathrm{F}$ can affect their germination and growth. Such knowledge is potentially useful for farmers to help them avoiding excessive application of $F$ containing fertilizers and irrigation with fluoride contaminated water as well as adoption of tolerant/suitable crops of interest to enhance crop productivity.

\section{Acknowledgements}

None.

\section{Conflict of interest}

The author declares there is no conflict of interest.

\section{References}

1. Tylenda CA. Toxicological profile for fuorides, hydrogen fluoride and fluorine (F). DIANE Publishing. 2011;383.
2. Kabata-Pendias A. Trace elements in soils and plants. 3rd ed. New York: CRC press. 2001.

3. Jha SK, Nayak AK, Sharma YK. Fluoride toxicity effects in onion (Allium cepa L.) grown in contaminated soils. Chemosphere. 2009;76(3):353356.

4. Symonds R, Rose W, Reed M. Contribution of $\mathrm{Cl}$ and $\mathrm{F}$ bearing gases to the atmosphere by volcanoes. Nature. 1988;334:415-418.

5. Elloumi N, Abdallah FB, Mezghani I, et al. Effect of fluoride on almond seedlings in culture solution. Fluoride. 2005;38(3):193-198.

6. Baunthiyal M, Ranghar S. Accumulation of fluoride by plants: potential for phytoremediation. Clean-Soil Air Water. 2015;43(1):127-132.

7. Barbier O, Arreola-Mendoza L, Del Razo LM. Molecular mechanisms of fluoride toxicity. Chem Biol Interact. 2010;188(2): 319-333.

8. Yadu B, Chandrakar V, Keshavkant S. Responses of Plants to Fluoride: An Overview of oxidative stress and defense mechanism. Fluoride. 2016;49(3 Pt 2):293-302.

9. Kaur J, Duffus C. The effect of sodium fluoride on cereal seed germination and seedling growth. Plant Cell and Environment. 1989;12(2):155-161.

10. Chandra P, Vishnoi N, Singh DP. Assessment of Fluoride Contamination of Water and Soil and its Phytotoxic Effect on the Growth Parameters in Selected Vegetable Crops. Global Journal of Applied Environmental Sciences. 2012;2(1):55-65. 
11. Maguire JD. Speed of germination-Aid in selection and evaluation for seedling emergence and vigour. Crop Science. 1962;2(1):176-177.

12. Abdul-Baki A, Anderson JD. Vigor determination in Soybean seed by multiple criteria. Crop Science. 1973;13(6):630-633.

13. Mohan R, Singh R, Singh PR. Effects of GA3 against Cd toxicity during germination in Blackgram. Proc APPSC Conference and Neo Botanica Convention. In: Mehta AS, Saran B, editors. Patna, India, 1996;87-90.

14. Hiscox JD, Israelstam GF. A method for the extraction of chlorophyll from leaf tissue without maceration. Canadian Journal of Botany. 1979;57(12):1332-1334.

15. Arnon DI. Copper enzymes in isolated Chloroplasts; Polyphenol oxidases in Beta vulgaris. Plant Physiology. 1949;24:1-15.

16. Lichtenthaler HK, Wellburn WR. Determination of total carotenoids and chlorophylls a and $\mathrm{b}$ in leaf extracts in different solvents. Biochemical Society Transactions. 1983;11(5):591-592.

17. Singh S, Singh J, Singh N. Studies on the impact of Fluoride toxicity on growth parameters of Raphanus sativus L. Indian J Sci Res. 2013;4(1):6163

18. Iram A, Khan TI. Effect of Sodium Fluoride on Seed Germination, Seedling Growth and Biochemistry of Abelmoschus esculentus. Journal of Plant Biochemistry and Physiology. 2016;4:170.

19. Shaddad MA, Radi AF, El-Enamy AE. Seed germination transpiration rate and growth criteria as affected by various concentrations of $\mathrm{CdCl}_{2}$, $\mathrm{NaF}$ and 2,4-DNP. Journal of Islamic Academy of Sciences. 1989;2(1):712.
20. Yu MH. Effects of fluoride on growth and soluble sugars in germinating mung bean (Vigna radiata) seeds. Fluoride. 1996;29(1):3-6.

21. Bhargava D, Bhardwaj N. Effect of sodium fluoride on seed germination and seedling growth of Triticum aestivum. Journal of Phytology. 2010;2(4):41-43.

22. Sabal D, Khan TI, Saxena R. Effect of sodium fluoride on cluster bean (Cyamopsis tetragonoloba) seed germination and seedling growth. Fluoride. 2006;39(3):228-230.

23. Davies MT, Port GR, Davison AW. Effects of dietary and gaseous fluoride on the aphid Aphis fabae. Environ Pollut. 1998;99(3):405-409.

24. Datta JK, Maitra A, Mondal NK, et al. Studies on the impact of fluoride toxicity on germination and seedling growth of gram seed (Cicer arietinum L. cv. Anuradha). Journal of Stress Physiology and Biochemistry. 2012;28(1):194-202.

25. Tomar S, Aery NC. Effect of sodium fluoride on seed germination, early seedling growth and biochemical constituents of Wheat. Journal of Environmental Biology. 2000;21(4):333-336.

26. Ram A, Verma P, Gadi BR. Effect of fluoride and salicylic acid on seedling growth and biochemical parameters of watermelon (Citrullus lanatus). Fluoride. 2014;47(1):49-55. 